\title{
Effect of Perception and Free Maternal Health Services on Antenatal Care Facilities Utilization in Selected Rural and Semi-Urban Communities of Ondo State, Nigeria
}

\author{
Francis Adegoke Akanbiemu ${ }^{1,2}$, Aderonke Manuwa-Olumide ${ }^{1}$, \\ Adeniyi Francis Fagbamigbe ${ }^{3^{*}}$ and Ayo Stephen Adebowale ${ }^{3}$ \\ ${ }^{1}$ Department of Community Medicine, Faculty of Public Health, College of Medicine, \\ University of Ibadan, Ibadan, Nigeria. \\ ${ }^{2}$ Ministry of Health, Ondo State Government of Nigeria, Nigeria. \\ ${ }^{3}$ Department of Epidemiology and Biostatistics, Faculty of Public Health, College of \\ Medicine, University of Ibadan, Ibadan, Nigeria.
}

Authors' contributions

This work was carried out in collaboration between all authors. Author FAA conceived the study, wrote introduction, actively involved in data collection and contributed to results writing. Author AMO reviewed relevant literatures, contributed to the introduction section and did repeated editorial review of the manuscript. Author AFF prepared the study design, analysed the data and wrote the results while author ASA was involved in methodology section and contributed to data analysis. All authors wrote the discussions section and reviewed the manuscript. All authors read and approved the final manuscript.

Research Article

Received $21^{\text {st }}$ November 2012

Accepted $4^{\text {th }}$ February 2013

Published $28^{\text {th }}$ February 2013

\section{ABSTRACT}

Aims: We aimed at assessing perception and effect of free maternal health services on the utilization of ANC services among women of child bearing age.

Study Design: A cross-sectional study involving 460 women aged 15-49 years who were currently pregnant or had their most recent birth within the previous five years prior the survey was conducted using a two-stage sampling technique.

Place of Study: Rural and semi-urban communities in Ondo State, Nigeria.

Methodology: We administered semi-structured interviewer questionnaire. Knowledge 
was classified as good if knowledge score is higher or equal to the mean score obtained from this study and poor if otherwise. A 5-point likert scale was used to measure respondents' perception. Respondents with scores less than the mean perception score from this study were classified as having negative perception and positive if otherwise. Descriptive statistics, Chi-square tests and logistic regression model were used for data analysis and significance level was set at $P=.05$.

Results: Mean age, knowledge score and perception score of the respondents were $29.8 \pm 7.3$ years, $6.0 \pm 1.2$ and $29.6 \pm 6.0$ respectively. Overall, $95.4 \%$ had utilized ANC facilities. Highest proportions $(55.0 \%)$ of those utilizing ANC were aged 20$30 y e a r s . A b o u t$ two fifth $(40.8 \%)$ reported that free ANC services was the main reason for choosing public ANC facilities. Almost two-third (63.0\%) of the respondents had good knowledge of ANC, while about $35.9 \%$ had positive perception towards free ANC services. Higher utilization of ANC services was observed among married or cohabiting women than the singles and widows $(P=.04)$. Logistic regression showed that Respondents' knowledge was significantly influenced by respondents' occupation, previous pregnancies, and religion.

Conclusion: Perception of women on free ANC utilization in the study area was negative although free ANC program instituted by government across the state enhanced ANC utilization. The government should sustain the policy on free maternal health services.

Keywords: Antenatal care facilities; utilization; free health programme; perception.

\section{INTRODUCTION}

Antenatal care (ANC) has long been recognized as an important intervention step in preventing maternal morbidity and mortality during pregnancy and in the post-partum period. It is assumed by many maternal and child health care services providers that ANC improves the general health condition of both mother and child during pregnancy, delivery and the puerperium. However, there are limited scientific studies showing this association, and where this exist, it only shows some aspect of the content of ANC as a useful screening tool in the early detection of high risk pregnancy-related health conditions [1-3]. However, despite these scientific evidences of ANC as a useful tool in improving maternal health, some pregnant women do not utilize it $[4,5]$.

The ANC remains one of the pillars of the safe motherhood Initiative and a core strategy in the Millennium Development Goals of preventing child mortality and improving maternal health. One of the purposes of antenatal care is to establish a relationship between a pregnant woman and health care providers. This will create avenue for positive interaction which enables the provider to identify risks that are amenable to interventions. Benefits of ANC may be more effective when its services are accessed early in pregnancy. Earlier research has established that timely and adequate prenatal care is effective in reducing the likelihood of low birth weight and other adverse pregnancy outcomes [4-6].

The proportion of women aged 15-49 who utilized ANC services in Nigeria stands at $58 \%$ with a wide range of disparity between North-West $31.1 \%$ and South-West $87.7 \%[7]$. Studies done in Japan show that only about $46.1 \%$ of women aged $15-49$ years utilized ANC[8], while women reported having received antenatal care from a provider for $48 \%$ of all live and still births in Bangladesh [9]. A national survey in Nigeria derived from the 2005 National 
HIVIAIDS and Reproductive Health Survey (NARHS) show that about three-fifths $(60.3 \%)$ of the respondents used antenatal services at least once during their most recent pregnancy [10].

World health organization (WHO) recommends at least four visits to antenatal care facilities throughout pregnancy. Evidence has shown that more than four visits are only recommended in case of complication [11,12]. Utilization of health facilities are determined by many factors. Maternal age, parity, income, standard of living of households, ANC users fees and travel distance to ante natal care provider are the common economic factors that have been cited by previous researchers [13-15]. Previous studies showed that the likelihood that a household will utilize health facilities is a function of its socioeconomic, demographic and supply variables and that substantial difference exist in utilization pattern by income class. In addition, these studies showed that "Households in the highest income quintile are approximately twice more likely to utilize private hospital services than those in the lowest, ceteris paribus [13-15].

Aside the socioeconomic factors influencing ANC, it is often believed that pregnant women's' knowledge and perception of importance of ANC determines its utilization. It was also reported that educated couples are more likely to switch from their cultural and religious ideology of leaving most events in their lives to fate and supernatural belief[16]. For instance, in Indonesia, it was demonstrated that improvement in ANC knowledge was significantly influenced by respondents' levels of education [17].

Radio and television access exposure were also shown to influence ANC as found in a study conducted in Bangladesh [18]. Also in Uganda, a study reported that ANC utilization was mainly affected by distance and lack of knowledge of the importance of ANC [19]. Similar study carried out in Islamabad, Pakistan[20] revealed that of the women who did not avail themselves of ANC, about three quarter cited ignorance of the importance of antenatal care as reason why they didn't utilize ANC.

To a great extent, knowledge and attitude determines the level of practice ANC. This was shown by a study in Kolkata (Indian) where nearly two third of the study group had either good or excellent knowledge, convenience, utilization and satisfaction of maternal health services. The study further showed that almost two thirds $(64.25 \%)$ of the women studied utilized ANC facilities because of the good knowledge demonstrated by them [21]. On the other hand, knowledge about antenatal care was found to be better among women who utilized antenatal care as compared to women who did not receive [22]. The implication of these studies is that knowledge improves utilization of ANC services and vice versa.

A Nicaragua study also found that women utilization of prenatal and delivery services is influenced by communal and individual perception regarding maternal care[23]. Women perception that facility-based care provides a safe environment for receiving care evolved from the quality of care they received and delivery outcome from previous pregnancies. Many women who experienced complications from previous birth or low parity had an increased fear and awareness of the risk involved in failing to seek care and thus sought care to avoid complications [23]. Therefore, perception of ANC and its utilization can be influenced by quality of care and previous pregnancy outcome.

Nigeria is ranked as one of the countries with the highest maternal mortality ratio in the world, with current figure of 545 per 100,000 live births and with a wide range of geographical disparity between 165 per100,000 live births in South West to 1,549 per100,000 live births in 
North East[24]. Published data on the effect of free maternal services and perception on ANC facilities utilization in Ondo state in general and in Okitipupa Local Government area in particular is lacking and this study is intended to provide such data. In view of the national need to meeting the Millennium Developmental Goal-4 (Reduce child mortality) and Goal-5 (Improve maternal health) in 2015, and also in line with global aspiration for attainment of optimal reproductive health, a good understanding of pregnant women's perception of ANC and other factors which influence the utilization of ANC facilities is germane. It is also imperative to know pregnant women attitude towards utilization of free health programme been offered in Ondo State. Therefore, the study is intended to explore the influence of free health programme and other factors on ANC facilities utilization in communities in Okitipupa Local Government Area, Ondo State.

\section{METHODOLOGIES}

This is a descriptive cross-sectional, community-based study conducted among women of reproductive age (15-49 years) in some selected rural and semi-urban communities in Okitipupa Local Government Area (LGA), Ondo State. A pre-tested structured interviewer administered questionnaire was used to obtain the relevant data. Multistage sampling procedures were used to select eligible respondents.

A semi-urban community was defined as having a population greater than 30,000 and having facilities like potable water, electricity, telephone services, secondary schools, banks, good intra-city roads network, while rural towns are those that have not met the criteria listed above. Two semi-urban communities (Ode-Aye and Okitipupa) and three rural communities Ikoya, lju-odo and Erinje were randomly selected using balloting. All houses having the eligible respondents in each selected town were listed using the 2006 National Population Census numbering system. Using sampling proportionate to size, 120 houses were selected from each of the semi-urban communities and 80 houses from each of the rural communities. Thereafter, a systematic random sampling method was used to select the houses. However, if a house has more than one eligible respondent, the respondent was selected using lottery method.

\subsection{Inclusion Criteria}

All selected women who had at least a baby delivery in the 5 years prior the surveyor currently pregnant were enrolled and interviewed.

\subsection{Measurement of the Dependent Variables}

Knowledge scores were based on 8 parameters, using Nigeria Standard Treatment Guide (2007). These were; (1) Assessment of risk in pregnancy; (2) Birth preparedness; (3) Physical examination; (4) Urine examination; (5) Blood pressure measurement; (6) Detecting fetal and maternal abnormalities; (7) Drugs for fetal and maternal wellbeing; (8) Immunization. Respondents were scored based on their ability to correctly state any of the above 8 parameters as either a purpose or service rendered in ANC visit. Each correct response to any of the parameter was scored 1 mark and each wrong response had 0 score. Knowledge score was grouped based on the mean score.

Also, a five-point Likert scale was used to measure respondents' perception. Mean perception score was measured based on the aggregate score. Respondents with scores 
less than the mean were classified as having negative perception, while those with scores greater than the mean were classified as having positive perception. Maximum obtainable attitudinal score was 40 .

\subsection{Data Collection and Analysis}

Descriptive statistics such as percentage or proportion were used to describe the quantitative/categorical variables. The Chi-square test was used for the bivariate analysis and the multivariate analysis was carried out using multiple logistic regression model while $p$-value less than 0.05 were considered to be statistically significant.

\section{RESULTS}

The mean age of the respondents was $29.8 \pm 7.3$ with majority being in the $20-29(46.3 \%)$ age group, while the least represented age group was ages $15-19$ years (6.5\%). Majority $(89.3 \%)$ of the respondents were presently married. Yoruba was the predominant ethnic group among the respondents representing $84.6 \%$. The respondents were mainly Christians $(87.6 \%)$. About a third of the respondents $(32.0 \%)$ were traders, the farmers constituted $17.6 \%$, while the business women constituted about a quarter $(24.8 \%)$ of the respondents. A close proportion (37.6\%\& $34.3 \%)$ of the respondents attained secondary and primary education respectively compared with tertiary $76(16.5 \%)$ and those with no formal education 53(11.5\%) as shown in Table 1.

\subsection{The Knowledge of Respondents with Regards to Antenatal Care (ANC)}

Knowledge of ANC shows that $98.0 \%$ of the respondents were aware of the term ANC, while almost half of the respondents got the information on ANC from health workers $(45.9 \%)$.

The mean knowledge score was $5.99 \pm 1.2$ and ranged from $0-8$. Those with scores less than the mean (i.e. <6.0) were classified as having poor knowledge, while those with scores greater than or equal to the mean $(\geq 6.0)$ were classified as having good knowledge. The responses to the knowledge-based questions on ANC were generally good as shown in Table 2. Majority of them had good knowledge on the purposes and services of ANC.

\subsection{Respondents' Perception of Antenatal Care}

Almost all the respondents (98.5\%) believe that ANC improves their health and that of their unborn child, while $94.4 \%$ believe that ANC improves pregnancy outcome. A greater proportion (96.2\%) of the respondents believes that ANC prevents delivery complications. About $53.5 \%$ of the respondent disagree that ANC is not very useful to multiparous women. However, about one third $(30.9 \%)$ of the respondent disagreed that women only registered for the purpose of where to deliver, while about three-quarter $(74.6 \%)$ agreed ANC can reduce morbidity and mortality in women. On whether ANC is necessary for purpose of treatment of minor illness during pregnancy; over three quarter (84.4\%) of the respondent agreed to the query. 
Table 1. Socio-demographic characteristics of respondents

\begin{tabular}{ll}
\hline Characteristics & Frequency $\mathbf{n}(\%)$ \\
\hline Location & \\
Urban & $222(48.3)$ \\
Rural & $238(51.7)$ \\
Age & Mean= $29.8 \pm 7.3$ \\
$15-19$ & $30(6.5)$ \\
$20-29$ & $213(46.3)$ \\
$30-39$ & $165(35.9)$ \\
40 \& Above & $52(11.3)$ \\
Marital Status & \\
Single & $7(1.5)$ \\
Married & $411(89.3)$ \\
Separated & $8(1.7)$ \\
Divorced & $19(4.1)$ \\
Cohabiting & $6(1.3)$ \\
Widow & $9(2.0)$ \\
Tribe & \\
Edo & $32(7.0)$ \\
Hausa & $9(2.0)$ \\
Igbo & $30(6.5)$ \\
Yoruba & $389(84.6)$ \\
Religion & \\
Christianity & \\
Islam & $403(87.6)$ \\
Traditional & $42(9.1)$ \\
Educational qualifications & $14(3.0)$ \\
No formal education & \\
Primary & \\
Secondary & $53(11.5)$ \\
Tertiary & $158(34.3)$ \\
Occupation & $173(37.6)$ \\
Trading & $76(16.5)$ \\
Farming & \\
Business & $147(32.0)$ \\
Civil servant & $81(17.6)$ \\
Onemployed & $114(24.8)$ \\
\hline & $63(13.7)$ \\
& $44(9.5)$ \\
& $11(2.4)$ \\
\hline
\end{tabular}


Table 2. Knowledge of ANC utilization

\begin{tabular}{lll}
\hline $\begin{array}{l}\text { Variable } \\
\text { Do you know about the followings in ANC? }\end{array}$ & $\begin{array}{l}\text { Yes } \\
\mathbf{n}(\%)\end{array}$ & $\begin{array}{l}\text { No } \\
\mathbf{n}(\%)\end{array}$ \\
\hline Assessment of risk in pregnancy & $395(85.9)$ & $65(14 . .1)$ \\
Birth preparedness & $290(63.0)$ & $170(37.0)$ \\
Physical examination & $241(52.4)$ & $219(47.6)$ \\
Urine examination & $351(76.3)$ & $109(23.7)$ \\
Blood pressure measurement & $453(98.5)$ & $7(1.50)$ \\
Detecting fetal and maternal abnormality & $288(62.6)$ & $172(37.4)$ \\
Drugs for fetal and maternal wellbeing & $438(93.0)$ & $22(7.0)$ \\
Immunization & $320(69.6)$ & $140(30.4)$ \\
Proportion of Poor Knowledge & $170(37.0)$ & \\
Proportion of Good Knowledge & $290(63.0)$ & \\
Mean Knowledge Score & $5.99 \pm 1.2$ & \\
\hline
\end{tabular}

Table 3. Perception of antenatal care activities

\begin{tabular}{|c|c|c|c|c|c|}
\hline & $\begin{array}{l}\text { Strongly } \\
\text { agree }\end{array}$ & Agree & $\begin{array}{l}\text { Don't } \\
\text { know }\end{array}$ & Disagree & $\begin{array}{l}\text { Strongly } \\
\text { disagree }\end{array}$ \\
\hline $\begin{array}{l}\text { ANC is very important to the } \\
\text { health of pregnant women } \\
\text { and their unborn child }\end{array}$ & $274(60.8)$ & $170(37.7)$ & $1 \quad(0.2)$ & $2(0.4)$ & $4(0.9)$ \\
\hline $\begin{array}{l}\text { ANC Improves pregnancy } \\
\text { outcome }\end{array}$ & $261(58.0)$ & $164(36.4)$ & $8(1.8)$ & $9(2.0)$ & $8(1.8)$ \\
\hline $\begin{array}{l}\text { ANC prevents delivery } \\
\text { complications }\end{array}$ & $267(59.3)$ & $166(36.9)$ & $3(0.7)$ & $4(0.9)$ & $10(2.2)$ \\
\hline $\begin{array}{l}\text { ANC is not very useful to } \\
\text { multiparous women }\end{array}$ & $13(2.9)$ & 108(23.9) & $89(19.7)$ & $127(28.2)$ & $114(25.3$ \\
\hline $\begin{array}{l}\text { You register for ANC only for } \\
\text { the purpose of where to } \\
\text { deliver }\end{array}$ & $99(22.0)$ & $189(42.0)$ & $23(5.1)$ & $95(21.1)$ & $44(9.8)$ \\
\hline $\begin{array}{l}\text { ANC is necessary for purpose } \\
\text { of treatment of minor illnesses } \\
\text { during pregnancy }\end{array}$ & $177(39.3)$ & $203(45.1)$ & $3(0.7)$ & $37(8.2)$ & $30(6.7)$ \\
\hline $\begin{array}{l}\text { ANC can reduce morbidity } \\
\text { and mortality in women }\end{array}$ & $236(52.4)$ & $10022.2)$ & $36(8.0)$ & $73(16.2)$ & $5(1.1)$ \\
\hline
\end{tabular}

\subsection{Practice of Antenatal Care}

As shown in Figure 1, over four fifth of the respondents (95.4\%), utilized ANC during their last pregnancy. 


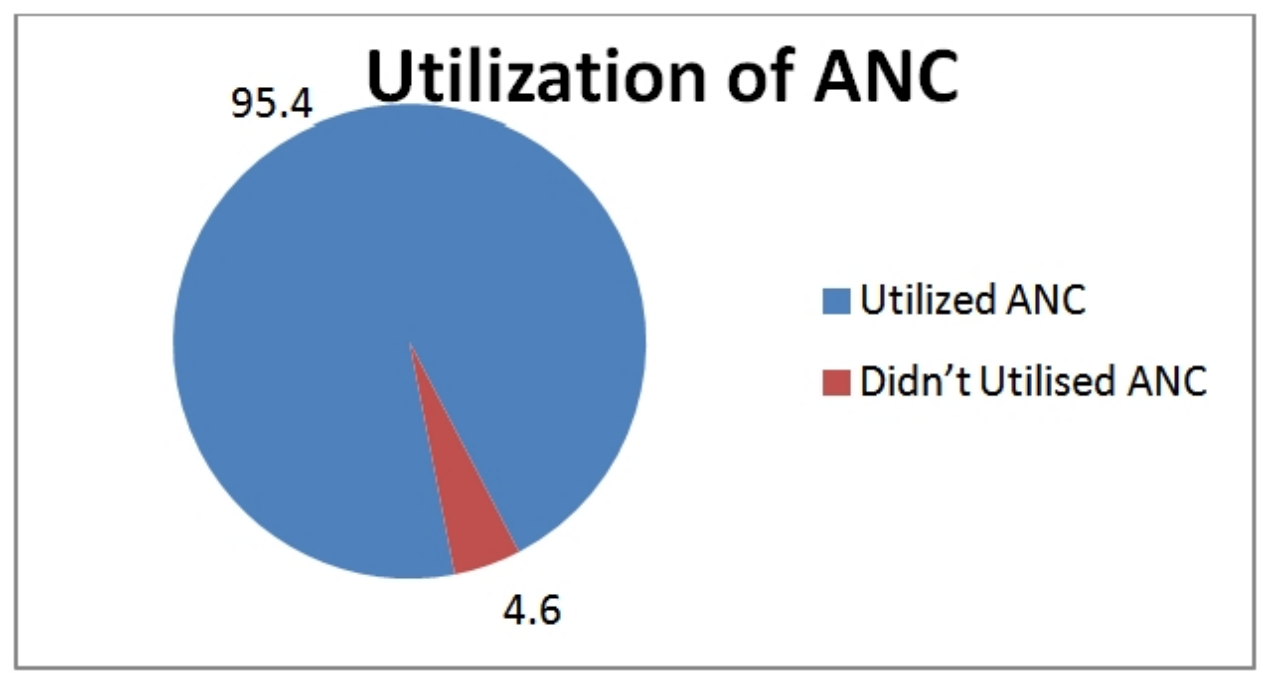

Figure 1. Pie chart showing respondents utilization of ANC during their last pregnancy

\subsection{Demographic Characteristics of Respondents and the Utilization of ANC}

Age was found to be associated with the utilization of ANC but women aged 20-29 were the highest numbers of users $(96.7 \%)$ when compared with the other age groups $\left(X^{2}=25.928\right.$, $3 \mathrm{df}, P<.001)$. Also attaining any level of education was significantly associated with ANC utilization as those with secondary education has the highest proportion of ANC utilization in their last pregnancy $(96.5 \%)$ as compared with those without formal education $\left(X^{2}=7.925\right.$, $d f$, $P=.048)$. In addition, Marital status was significantly associated with the utilization of ANC as those who were married had the highest proportion $394(96.1 \%)$ of users when compared with the singles' $\left(x^{2}=16.77,5 \mathrm{df}, P=.005\right)$.

\subsection{Relationship between Respondents' Knowledge and Perception of ANC on Practice of ANC}

Previous delivery of a healthy baby was the factor found to have the strongest influence on the utilization of any ANC facilities, and also attitude $\left(X^{2}=9.806,1 \mathrm{df}, P=.02\right)$ and husband educational status $\left(X^{2}=7.824,3 \mathrm{df}, P=.05\right)$. Knowledge of ANC was not found to be associated with ANC utilization. This is shown in Table 4 below. Table 5 also showed the relationship between respondents' socio-demographic factors and their utilization of ANC facilities. 
Table 4. Association between respondents' knowledge and perception of ANC and the utilization of any ANC facilities

\begin{tabular}{|c|c|c|c|c|c|}
\hline Characteristics & $\%$ of 460 & $\begin{array}{l}\text { Received ANC in } \\
\text { pregnancy? } \\
\text { Yes }\end{array}$ & $\begin{array}{l}\text { the last } \\
\text { No }\end{array}$ & $X^{2}, \mathrm{df}$ & p-value \\
\hline $\begin{array}{l}\text { Previous delivery of } \\
\text { a healthy baby } \\
\text { Knowledge }\end{array}$ & 95.2 & $385(87.9)$ & $53(12.1)$ & $51.229,1$ & .00 \\
\hline Poor knowledge & 37.0 & $165(97.6)$ & $4(2.4)$ & $2.988,1$ & .08 \\
\hline $\begin{array}{l}\text { Good knowledge } \\
\text { Perception }\end{array}$ & 63.0 & $273(94.1)$ & $17(5.9)$ & & \\
\hline Positive Perception & 35.9 & $146(91.2)$ & $14(8.8)$ & $9.806,1$ & .02 \\
\hline Negative Perception & 64.1 & $292(97.7)$ & $7(2.3)$ & & \\
\hline
\end{tabular}

Table 5. Relationship between respondents' demographic factors and their utilization of ANC facilities

\begin{tabular}{|c|c|c|c|c|}
\hline \multirow[t]{2}{*}{ Characteristics } & \multicolumn{2}{|c|}{ Received ANC in the last pregnancy? } & \multirow[t]{2}{*}{$\mathrm{X}^{2}, \mathrm{Df}$} & \multirow[t]{2}{*}{ p-value } \\
\hline & & & & \\
\hline Age (years) & & & $25.928,3$ & .000 \\
\hline$<20$ & $23(76.7)$ & $7(23.3)$ & & \\
\hline $20-29$ & $206(96.7)$ & $7(3.3)$ & & \\
\hline $30-39$ & $159(97.0)$ & $5(3.0)$ & & \\
\hline 40 and above & $50(96.2)$ & $2(3.8)$ & & \\
\hline Educational status & & & $7.925,3$ & .048 \\
\hline None & $47 \quad(88.7)$ & $6(11.3)$ & & \\
\hline Primary & $150(94.9)$ & $8(5.1)$ & & \\
\hline Secondary & $166(96.5)$ & $6(3.5)$ & & \\
\hline Tertiary & $75(98.7)$ & $1(1.3)$ & & \\
\hline Marital status & & & $16.769,5$ & .005 \\
\hline Married & $394(96.1)$ & 16(3.9) & & \\
\hline Single & $5(71.4)$ & $2(28.6)$ & & \\
\hline Divorced & $18(94.7)$ & $1(5.3)$ & & \\
\hline Widow & $7 \quad(77.8$ & $2(22.2)$ & & \\
\hline Separated & $8(100.0)$ & $0(0.0)$ & & \\
\hline Cohabiting & $6 \quad(100.0)$ & $0(0.0)$ & & \\
\hline Occupation & & & $10.487,5$ & 0.063 \\
\hline Trading & $139(94.6)$ & $8(5.4)$ & & \\
\hline Farming & $80(98.8)$ & $1(1.2)$ & & \\
\hline Business & $109(95.6)$ & $5(4.4)$ & & \\
\hline Civil servant & $62(98.4)$ & $1(1.6)$ & & \\
\hline Unemployed & $39(90.7)$ & $4(9.3)$ & & \\
\hline Others & $9(81.8)$ & $2(18.2)$ & & \\
\hline $\begin{array}{l}\text { Husband Educational } \\
\text { status }\end{array}$ & & & $7.824,3$ & .05 \\
\hline None & $39(86.6)$ & $5(11.4)$ & & \\
\hline Primary & $96(93.2)$ & $7(6.8)$ & & \\
\hline Secondary & $175(96.7)$ & $6(3.3)$ & & \\
\hline Tertiary & $124(91.6)$ & $3(2.4)$ & & \\
\hline
\end{tabular}




\subsection{Factors Affecting Respondents Perception and Knowledge of ANC}

Respondents' knowledge is significantly influenced by respondents' type of occupation, number of previous pregnancy, religion practiced, husband's occupation and educational attainment $(p<.001)$. Respondents who were civil servants were two and half times more likely to have a good knowledge of ANC than their counterparts who were traders. Respondents whose husband had no education were about eleven times more likely to have good knowledge than those whose husband had tertiary education. Also respondents whose husbands were civil servants and farmers were about twice more likely and thrice less likely respectively to have good knowledge of ANC. Educational status of respondents, their occupation, number of previous pregnancies and whether receive ANC or not significantly affects their perceptions of ANC. Respondents who had received ANC services were about 26 times more likely to have positive perception of ANC than those who had not $(p<.001)$. Uneducated respondents were over twelve times more likely than respondents who had tertiary education to have positive perception of ANC services (Table 6).

Table 6. Effects of socio-demographic variables on respondents' knowledge and perception of ANC and the utilization of any ANC facilities

\begin{tabular}{|c|c|c|c|c|}
\hline Characteristics & $\begin{array}{l}\text { Knowledge } \\
\text { Aor( } 95 \% \mathrm{Cl})\end{array}$ & p-value & $\begin{array}{l}\text { Perception } \\
\text { AOR(95\%CI) }\end{array}$ & p-value \\
\hline \multicolumn{5}{|c|}{ Educational status } \\
\hline None & -- & -- & $12.30(3.91-38.8)$ & .00 \\
\hline Primary & -- & -- & $4.80(1.79-12.8)$ & .00 \\
\hline Secondary & -- & -- & $3.74(1.50-9.28)$ & .00 \\
\hline Tertiary & -- & -- & Ref & \\
\hline \multicolumn{5}{|l|}{ Occupation } \\
\hline Trading & Ref & & Ref & \\
\hline Farming & $1.13(0.57-2.23)$ & .72 & $0.55(0.27-1.09)$ & .08 \\
\hline Business & $0.71(0.39-1.32)$ & .28 & $1.51(0.84-2.70)$ & .17 \\
\hline Civil servant & $2.58(1.16-5.70)$ & .02 & $2.51(1.01-6.30)$ & .04 \\
\hline Unemployed & $0.70(0.30-1.65)$ & .41 & $1.95(0.85-4.48)$ & .12 \\
\hline Others & $5.02(0.47-53.2)$ & .18 & $0.42(0.05-3.68)$ & .44 \\
\hline \multicolumn{5}{|c|}{$\begin{array}{l}\text { Husband } \\
\text { educational status }\end{array}$} \\
\hline None & $11.4(3.81-34.2)$ & .00 & -- & -- \\
\hline Primary & $10.1(4.13-24.7)$ & .00 & -- & -- \\
\hline Secondary & $6.87(3.23-14.6)$ & .00 & -- & -- \\
\hline Tertiary & Ref & & & \\
\hline \multicolumn{5}{|l|}{ Husband } \\
\hline Occupation & Ref & & & \\
\hline Trading & $0.36(0.16-0.82)$ & .01 & -- & -- \\
\hline Farming & $0.82(0.35-1.93)$ & .66 & -- & -- \\
\hline Business & $2.34(0.86-6.39)$ & .09 & -- & -- \\
\hline Civil servant & $2.08(0.83-5.21)$ & .12 & -- & -- \\
\hline Unemployed & $6.60(0.55-79.5)$ & .14 & -- & -- \\
\hline Others & & & & \\
\hline \multicolumn{5}{|l|}{ Religion } \\
\hline Christianity & Ref & & & \\
\hline Islam & $0.83(0.38-1.84)$ & .65 & -- & -- \\
\hline
\end{tabular}




\begin{tabular}{lllll}
\hline $\begin{array}{l}\text { Traditional } \\
\text { No of Previous }\end{array}$ & $8.18(1.09-61.6)$ & .04 & -- & -- \\
$\begin{array}{l}\text { Pregnancy } \\
\text { Once }\end{array}$ & $1.10(0.42-2.86)$ & .85 & $3.12(1.41-6.91)$ & .00 \\
Twice & $3.46(1.62-7.41)$ & .00 & $1.36(0.71-2.62)$ & .35 \\
Thrice & $2.48(1.12-5.28)$ & .02 & $1.17(0.59-2.33)$ & .64 \\
Four times & $1.24(0.59-2.46)$ & .61 & $0.98(0.49-1.96)$ & .96 \\
Above four times & Ref & & & \\
Ever received ANC & & -- & Ref & \\
No & -- & -- & $26.2(3.13-218.9)$ & .00 \\
Yes & -- & & & \\
\hline
\end{tabular}

\subsection{Types of ANC facilities Utilized (Public and Private)}

In Table 7 , three quarter $(75 \%)$ of the respondents utilized public ANC health facilities (general/state specialist hospital and health Centre's), while only one quarter utilized other facilities like private hospitals, home/birth attendants and faith-based organizations in decreasing order. Very few women (1.5\%) did not utilize any ANC facility.

Table 7. Types of ANC facilities utilized (public and private)

\begin{tabular}{ll}
\hline ANC Facilities utilized & Frequency (\%) \\
\hline General/State Specialist Hospital & $200(43.5)$ \\
Health Centers & $145(31.5)$ \\
Private Hospital & $74(16.1)$ \\
Faith Based Organization (churches/mission homes and mosque) & $10(2.2)$ \\
Home/Birth attendants & $24(5.2)$ \\
None & $7(1.5)$ \\
Total & 460 \\
\hline
\end{tabular}

\subsection{Main Reason for Utilizing Public ANC}

About $41 \%$ of the respondent stated that Ondo State free health programme for pregnant women was the single reason why they utilized public health facilities, followed distantly by satisfactory treatment of illnesses during pregnancy (Table 8).

\subsection{Factors Affecting Utilization of ANC facilities}

In Table 9, we showed the proportions of respondents who would consider the different reasons before making a choice of ANC facility to be used. Majority (85.2\%) of the respondents claimed that previous delivery of a healthy baby is a factor they would consider for utilizing any ANC, followed by availability of immunization services $(85.0 \%)$, while only $53.6 \%$ would consider "husband's instruction" as the reason for choosing any ANC (12.7\%), 
Table 8. Respondents' Single reason for using public ANC facilities

\begin{tabular}{cll}
\hline Single reason for using public ANC facilities & Frequency & \% \\
\hline Free Health for pregnant women & 161 & 40.8 \\
Satisfactory treatment of illness & 50 & 12.7 \\
Health education during ANC visit & 37 & 9.4 \\
Previous delivery of a healthy baby & 27 & 6.8 \\
Adequate number of health workers & 25 & 6.3 \\
Availability of immunizations & 24 & 6.1 \\
Husband instructions & 12 & 3.0 \\
Politeness of health workers & 11 & 2.8 \\
Availability of family planning services & 10 & 2.5 \\
Avail. of post natal services & 10 & 2.5 \\
Advocacies by health workers & 9 & 2.3 \\
Facility is supernaturally endowed & 6 & 1.5 \\
Short distance to house & 6 & 1.5 \\
Beauty/cleanliness of ANC facility & 5 & 1.3 \\
Propaganda by political office holders & 2 & 0.5 \\
Total & 395 & 100.0 \\
\hline
\end{tabular}

Table 9. Reasons for utilizing any ANC facilities

\begin{tabular}{lll}
\hline Reasons & Frequency & $\%$ \\
\hline Previous delivery of a healthy baby & 392 & 85.2 \\
Availability of immunization services & 390 & 85.0 \\
Adequate numbers of nurses/midwives & 382 & 83.2 \\
Satisfactory treatment of illness in pregnancy & 370 & 80.8 \\
Politeness of health workers & 348 & 75.5 \\
Postnatal clinic availability & 345 & 75.3 \\
Adequate numbers of doctors & 343 & 74.7 \\
Health education & 333 & 72.5 \\
Beauty and cleanliness of health facilities & 330 & 72.1 \\
Advocacy of health workers & 308 & 67.1 \\
Family planning clinic availability & 268 & 58.4 \\
Husband instruction & 246 & 53.6 \\
\hline
\end{tabular}

\subsection{Factors Influencing Choice of either Public or Private Health Facilities.}

The respondents' husband's educational status was significantly associated with the type of ANC facilities utilized $\left(X^{2}=11.344,3 \mathrm{df}, P=.01\right)$, while knowledge was not found to be associated with the type of facilities utilized. In other words, the preference to use either public health facilities or any other type was not significantly associated with knowledge $\left(x^{2}=\right.$ 
$0.156,1 \mathrm{df}, P=.69)$. Attitude was also not found to be associated with the type of facilities utilized $\left(x^{2}=0.312,1 \mathrm{df}, P=.31\right)$, (Table 10).

Table 10. Factors influencing choice of either public or private health facilities.

\begin{tabular}{lllll}
\hline Variable & Place of ANC utilization & & \\
& $\begin{array}{l}\text { Public health } \\
\text { facilities }\end{array}$ & $\begin{array}{l}\text { Other } \\
\text { places }\end{array}$ & $\mathbf{X}^{2}$ & $\begin{array}{l}\text { P- } \\
\text { value }\end{array}$ \\
\hline $\begin{array}{llll}\text { Respondents' educational qualifications } \\
\text { No formal education }\end{array}$ & $37(69.8)$ & $16(30.2)$ & $7.307,3$ & 0.06 \\
$\begin{array}{l}\text { Primary education } \\
\text { Secondary }\end{array}$ & $111(70.3)$ & $47(29.7)$ & & \\
Tertiary & $132(76.3)$ & $41(23.7)$ & & \\
Husband's educational qualifications & $65(85.5)$ & $11(14.5)$ & & \\
No formal education & $30(68.2)$ & $14(31.8)$ & $11.344,3$ & 0.01 \\
Primary & $75(72.8)$ & $28(27.2)$ & & \\
Secondary & $128(70.7)$ & $53(29.3)$ & & \\
Tertiary & $110(85.9)$ & $18(14.1)$ & & \\
Respondent marital status & $313(76.2)$ & $98(23.8)$ & $3.498,1$ & 0.06 \\
Married & $32(64.0)$ & $18(36.0)$ & & \\
Not married & $129(75.9)$ & $41(24.1)$ & $0.156,1$ & 0.69 \\
Knowledge & $216(74.2)$ & $75(25.8)$ & & \\
Poor knowledge & $116(72.0)$ & $45(28.0)$ & $1.021,1$ & 0.31 \\
Good knowledge & $229(76.3)$ & $71(23.7)$ & & \\
$\begin{array}{l}\text { Perception } \\
\text { Negative Perception }\end{array}$ & & & & \\
Positive Perception & & & \\
\hline
\end{tabular}

\section{DISCUSSION}

Our study showed a high usage of ANC facilities (95.4\%). We found that the single main reason why respondents patronize a public ANC facility is the newly introduced health services in the study area. Almost two-thirds of the respondents had good knowledge of ANC while less than half had positive perception of ANC. Factors influencing good knowledge of ANC include respondents number of previous deliveries, occupation, religion and their husband's occupation and level of education.

The mean age of respondents who were either currently pregnant or had had at least one child delivery within the last five years was $29.8 \pm 7.3$ years. This is similar to a study done in

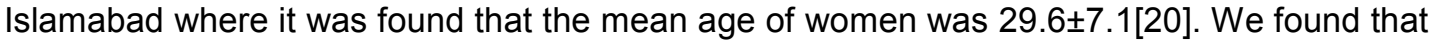
ANC use increased with age. This is similar to reports of Nigeria Demographic and Health Survey (NDHS), 2008 which reported that "Mother's age at birth is related to use of professional antenatal care services, increasing from $45 \%$ among women under age 20 at the time of the birth to $61 \%$ among women age $20-34$, and then declined to $55 \%$ among older mothers age 35-49"[24].

The present study showed that the knowledge of the respondent on the awareness, purpose and services of ANC was generally good (63.0\%). This finding is in agreement with a study in Kolkata, Indian where over $60.0 \%$ of women have good knowledge of ANC[21]. In our study, health workers, constituted the greatest source of information on ANC $45.9 \%$, 
followed by news media, $19.7 \%$. The impact of news media has assumed this relative importance as a source of ANC information because it was a major channel used by Ondo State political office holders to propagate the free ANC services in their public health facilities. Majority of the respondents indicated that ANC is meant to assess the health of pregnant women and their unborn child. Most respondent explained correctly that their blood pressures, weight, temperature and laboratory test were routinely done for them including physical examinations to determine the health status of their un-born baby. Some mentioned that health talk was regularly given to them during each visits especially on family planning. Immunization against tetanus was reported to be given to them during ANC visit.

However, despite the level of good knowledge of ANC found in our study, we did not find knowledge as a singular factor that could influence the utilization of ANC facilities. This finding is inconsistent with that in Japan where knowledge was found to be sole factor associated with ANC utilization. In Ethiopia, it was shown that non attendant of ANC was associated with poor knowledge of ANC [25]. In addition, a study carried out in Islamabad revealed that of the women who did not avail themselves of antenatal care, $75.5 \%$ cited ignorance about the importance of antenatal care [20].

Perception of ANC was predominantly negative though $96.5 \%$ believed that attending ANC improves their health and that of their unborn child. In addition $62.6 \%$ agreed that they register for ANC for the purpose of where to deliver. They also positively perceived that ANC can reduce morbidity and mortality in women. Majority of the respondents believed that ANC improves pregnancy outcome. This negative perception may not be unconnected with the relatively large number of the respondents who had secondary education, because education has been associated with increasing perception of ANC use. We found significant association between perception and ANC utilization. This finding agreed with the study in Japan which saw good perception as the most valuable precondition for any healthy behaviour and that women who had a positive perception towards ANC had a higher proportion of ANC visits compared with those with a negative perception[8].

Another outcome of our study was that public (Government) health facilities were the preferred choice among the ANC facilities used by majority of the respondents. Among reasons chosen by the respondents, free health services was the most stated reason for utilizing public health facilities, followed distantly by satisfactory treatment of illnesses during pregnancy. This could be due to the lessening of economic burden by the free health services programme in Ondo state as reported by earlier researcher which showed that economic factors are proportionally associated with ANC utilization [26]. However, economic reason was not found to be directly associated with the utilization of public health facilities in this study.

Previous delivery of healthy babies was the most single important factor that was positively associated with the utilization of all ANC facilities whether public or private. This is understandable because the final most cherished outcome of every pregnancy is delivery of a live baby and women may care less about what else is achieved once there were no associated complications throughout pregnancy period and at delivery.

We also found that respondents' knowledge is significantly influenced by respondents' type of occupation, number of previous pregnancy, religion practiced, husband's occupation and educational attainment. Also respondents whose husbands were civil servants and farmers were about twice more likely and thrice less likely respectively to have good knowledge of ANC than the traders. This is understandable as most civil servants are educated while most 
farmers had no education, hence no exposure to ANC activities. Educational status of respondents, their occupation, number of previous pregnancies and whether receives ANC or not significantly affects respondents' perceptions of ANC. Unlike in knowledge of ANC, uneducated respondents were over twelve times more likely than respondents who had tertiary education to have positive perception of ANC services. This could be due to the facts that, the educated respondent were getting far less than they expected from ANC.

\section{CONCLUSION}

This study showed that free health services for pregnant women in Ondo State were the main determinant of the utilization of public ANC facilities in Okitipupa LGA, while previous safe delivery of a healthy baby was the main reason for the utilization of any ANC facilities (public or private). Knowledge of ANC was good as the respondents excellently demonstrated that they knew the term ANC, its purposes and services. High proportion of the women responded positively to attitudinal questions on ANC and their perception on ANC was generally considered positive.

\section{CONSENT}

All authors declare that 'written informed consent was obtained from the patient (or other approved parties) for publication of this case report and accompanying images.

\section{ETHICAL CONSIDERATIONS}

Ethical approval for the study was obtained from the Ondo State Ethical Review committee of the Ministry of Health, Akure. Purpose and implication of the research were explained to the participants. Written informed consents were obtained from all the participants at the onset of the study and all information were treated with strict confidentiality.

\section{RECOMMENDATIONS}

The Ondo State Governments should sustain the free health services programme for pregnant women. From the perception of the respondents, the Ondo State Government should employ and motivate more nurses, midwives and doctors to ensure effective delivery of ANC services.

Factors such as risk identification and management with good delivery practices by health workers should be strengthened to ensure safe and healthy delivery of babies - an outcome strongly seen by respondents as the strongest single reason for the utilization of any ANC services.

\section{COMPETING INTERESTS}

Authors have declared that no competing interests exist.

\section{REFERENCES}

1. Goodburn E, McDonagh M. Maternal Health and Health sector Reform: opportunities and challenges. Safe Motherhood Strategies: a review of the evidence. Studies in Health Services Organisation \& Policy. 2001;17. 
2. NHS. Your Antenatal care. Pregnancy and baby 2012 [cited 2013 January ]. Available from:http://www.nhs.uk/conditions/pregnancy-and-baby-/pages/antenatal-midwifecare-pregnant.aspx.

3. Villar JCG, Khan-Neelofur D, Piaggio G, Gülmezoglu M. Patterns of routine antenatal care for low-risk pregnancy. Cochrane Database Syst Rev.Department of Reproductive Health and Research, World Health Organisation, Avenue Appia, Geneva, Switzerland, CH-1211. 2001;4(CD000934).

4. Greenberg RS. The Impact of Prenatal Care in Different Social Groups. . American Journal of Obstetrics and Gynecology. 1983;145(7):797-801.

5. Thomas AL, Verna M Keith, Mary Lou Gutierrez. Black/White Differences in Prenatal Care Utilization: An Assessment of Predisposing and Enabling Factors Health Services Research. 1995;30(1).

6. Gortmaker SL. The Effects of Prenatal Care upon the Health of the New born. American Journal of Public Health 69(7):653-60. American Journal of Public Health 69. 1979;69(7):653-60.

7. NDHS, Nigeria Demographic and Health Survey, 2008 A. NPC, Nigeria, Editor 2009, National Population Commission and ICF Macro.

8. $\mathrm{YE} \mathrm{Y,} \mathrm{et} \mathrm{al.} \mathrm{Factors} \mathrm{affecting} \mathrm{the} \mathrm{utilization} \mathrm{of} \mathrm{antenatal} \mathrm{care} \mathrm{services} \mathrm{among} \mathrm{women}$ in Kham district, Xiengkhouang province. J. Med. Sci. 2010;72:23-33.

9. Paul BK, Rumsey DJ, Utilization of health facilities and trained birth attendants for childbirth in rural Bangladesh: an empirical study.Social Science \& Medicine. 2002;54(12).

10. Health, N.F.M.o., National HIVIAIDS \& reproductive health survey (NARHS): Nigeria 2005. Federal Republic of Nigeria; 2006.

11. Villar, J.e.a., WHO antenatal care randomized trial for the evaluation of a new model of routine antenatal care The Lancet. 2001;357:1565-1570.

12. WHO, World Health Organization antenatal care randomized trial: manual for the implementation of the new model. Geneva: WHO Programme to Map Best Reproductive Health Practices; 2002.

13. Russo G, Herrin AN, Pons MC. Household healthcare facility utilization in the Philippines. Asia Pac J Public Health. 1996;9(6).

14. Adekunle $\mathrm{C}$, et al. Patterns of maternity care among women in Ondo States, Nigeria. In Determinants of health and mortality in Africa. Allan G. Hill, Demographic and Health Survey Further Analysis Series. New York:The Population Council. 1990;10(145).

15. Mekonnen Y, Asnaketch M. Utilization of Maternal Health Care Services in Ethiopia. Calverton, Maryland, USA: ORC Macro; 2002.

16. Belay TB, David PL. The influence of husbands' approval on women's use of prenatal care: Results from Yirgalem and Jimma towns, south west Ethiopia. Ethiop.J.Health Dev. 2000;20(2):84-92.

17. Nuraini E. Improving Knowledge of Antenatal Care among Pregnant Women: A Field Trial in Central Java, Indonesia. Asia-Pacific Journal of Public Health. 2005;17(1).

18. Mosiur R, I.R.a.I.A.Z., Rural-urban differentials of utilization of ante-natal health care services in Bangladesh Health policy and Development Journal, December, 2008;6(3).

19. Ankunda R, et al. Women's Perceptions of ANC and Delivery Care Services, A Community Perspective. Future Health Systems Study; 2008.

20. Alim AY, et al. Factors affecting utilization of Antenatal Care among women in urban slum areas of Islamabad. Department of Community Health Sciences, Shifa College of Medicine, Islamabad, Pakistan; 2004. 
21. Banerjee B. A Qualitative Analysis of Maternal and Child Health Services of an Urban Health Centre, By Assessing Client Perception In Terms of Awareness, Satisfaction And Service Utilization. Indian Journal of Community Medicine. 2003;28(4).

22. Nisar N, White F. Factors affecting utilization of Antenatal Care among reproductive age group Women (15-49 years) in an urban squatter settlement of Karachi. Journal of Pakistan Medical Association; 2008.

23. Lubbock LA SR. Utilization of maternal health care services in the department of Matagalpa, Nicaragua Nicaragua. vol 24(2):75-84. Rev Panam Salud Publica., 2008;24(2):75-84.

24. NPC, ICF-Macro, Nigeria Demographic and Health Survey, 2008 National Population Commission (NPC) and ICF Macro, Abuja, Nigeria; 2009.

25. Hayelom K, Sathya, Susuman. Factors Affecting Antenatal Care Attendance in Maichew Town, Southern Tigray. Addis Ababa University; 2008.

26. Russo G, Herrin AN, Pons MC. Household healthcare facility utilization in the Philippines. Asia Pac J Public Health.1996:9(6).

(c) 2013 Akanbiemu et al.; This is an Open Access article distributed under the terms of the Creative Commons Attribution License (http://creativecommons.org/licenses/by/3.0), which permits unrestricted use, distribution, and reproduction in any medium, provided the original work is properly cited.

Peer-review history:

The peer review history for this paper can be accessed here:

http://www.sciencedomain.org/review-history.php?iid=194\&id=12\&aid=1009 